\title{
New Family of Two-dimensional Zeolites Prepared from the Intermediate Layered Precursor IPC-3P Obtained during the Synthesis of TUN Zeolite
}

\author{
Martin Kubů ${ }^{[a]}$ Wieslaw J. Roth, ${ }^{[a]}$ Heather F. Greer,${ }^{[b]}$ Wuzong Zhou, ${ }^{[b]}$ Russell E. Morris, ${ }^{[b]}$ Jan \\ Přech, ${ }^{[a]}$ and Jiří Čejka**a]
}

Dedication ((optional))

\begin{abstract}
The crystallization of zeolite TUN with 1,4-bis(N-methylpyrrolidinium)butane as template proceeds via an intermediate, designated IPC-3P, following the Ostwald rule of successsive transformations. This apparently layered transient product has been thoroughly investigated and found to consist of MWW monolayers stacked without alignment in register, i.e. disordered compared with MCM-22P. The structure was confirmed based on $\mathrm{X}$-ray diffraction and HRTEM analysis. Layered zeolite precursor IPC-3P can be swollen and pillared affording
\end{abstract}

combined micro- and mesoporous material with enhanced BET surface area $\left(685 \mathrm{~m}^{2} / \mathrm{g}\right)$ and greater accessibility of Brønsted acid sites for bulky molecules. The latter was probed with 2,6-di-tert-butylpyridine (DTBP). IPC$3 \mathrm{P}$ and its modification create a new layered zeolite sub-family belonging to the MWW family. FTIR data indicate that (Al)MWW materials: MCM-22 and IPC-3 with $\mathrm{Si} / \mathrm{Al}>20$ exhibit lower relative ratio of Brønsted to Lewis acid sites than MCM-22 with $\mathrm{Si} / \mathrm{Al}$ around 13 , namely less than 2 vs. $>3$, respectively. This is maintained even upon pillaring and warrants further exploration of materials like IPC-3P with higher $\mathrm{Al}$ content. The unique XRD features of IPC-3P indicating mis-aligned stacking of layers and distinct from MCM-22P, are also seen in other MWW materials like EMM10P, HM-MCM-22 (hexamethonium templated MCM-22), ITQ-30 and UZM-8 suggesting need for more detailed study of their identity and properties.

\section{Keywords: TUN $・$ IPC-3 - MCM-} $22 \cdot$ Two-dimensional zeolites

\section{Introduction}

Zeolites represent an important group of inorganic crystalline microporous materials utilized in numerous large-scale chemical technologies as heterogeneous catalysts due to their adjustable acidity, high-temperature stability, and shape-selective properties. ${ }^{[1-4]}$ Catalytic applications of zeolites cover a broad range of reactions, from

[a] Dr. M. Kubů, Dr. W. J. Roth, J. Přech, Prof. Dr. J. Čejka Department of Synthesis and Catalysis

J. Heyrovský Institute of Physical Chemistry, Academy of Sciences of the Czech Republic, v.v.i.

Dolejškova 3, CZ-182 23 Prague 8, Czech Republic

Fax: (+420) 286582307

E-mail: jiri.cejka@jh-inst.cas.cz

[b] H. F. Greer, Prof. W. Zhou, Prof. R. E. Morris

EaStCHEM School of Chemistry, University of St Andrews St Andrews KY16 9ST, Scotland

((If supporting information is submitted, please include the following line:))

Supporting information for this article is available on the WWW under http://www.chemeurj.org/ or from the author. petroleum refining, petrochemistry, to biomass upgrade and fine chemical synthesis. ${ }^{[5-9]}$ The size of zeolite channels, in practice below about $1 \mathrm{~nm}$, limits accessibility of the active sites located in these channels for bulky reactants. One of the ways to overcome this disadvantage is to enlarge the accessible internal surface of zeolites. This can be achieved by either decreasing the crystal size, ${ }^{[10-12]}$ the discovery of zeolites with larger pores ${ }^{[13,14]}$ or by the formation of thin zeolites layers. ${ }^{[10,15,16]}$ It should be stressed that the first and last approaches may be accompanied with potentially detrimental effects such as reduced stability and loss of shape selectivity, especially in comparison to optimized parent zeolite application. Conventionally, zeolites have been thought of as uninterrupted 3D framework structures, but in past two decades they gradually revealed a new "dimension" as so-called two-dimensional (2D) zeolites. This is associated with ordered zeolite frameworks formed via lamellar precursors, ${ }^{[17-19]}$ which have been usually discovered using novel structure direct agents, SDAs ${ }^{[10]}$. At least ten different structural types of zeolites have shown formation via 2D lamellar precursors either as the only pathway observed to date or in addition to the standard direct assembly/crystallization in 3D as complete framework. Thus, a steadily increasing number of frameworks is found to be formed via transformation/recrystallization of an intermediate with evident lamellar nature, for example $\mathrm{MWW},{ }^{[20]} \mathrm{TUN},{ }^{[21]}$ FER. ${ }^{[22]}$ 
This generates zeolite families derived from a particular zeolite layer. These new families based on modified layered zeolite precursors, especially the expanded ones, offer interesting opportunities for catalyzing reactions of bulky substrate molecules. ${ }^{[12]}$ The postsynthesis expansion of zeolite precursors often requires high alkaline media, ${ }^{[23]}$ typically in the $\mathrm{pH}$ range up to 13 . Kresge and coworkers $^{[24,25]}$ demonstrated a method to swell MCM-22P by treatment with a long chain cationic surfactant (hexadecyl trimethyl ammonium) in the hydroxide form or in the mixture of its halide salt with a base (tetrapropyl ammonium hydroxide, TPA-OH) under high $\mathrm{pH}$ and at elevated temperatures. The swollen material was subsequently pillared to produce MCM-36 $6^{[24]}$ with micro- and mesopores and high activity in acid catalyzed reactions. The swellling and pillaring of MCM-22P represent procedures of considerable fundamental importance for preparation of new zeolite-based materials. MCM-36 showed a better catalytic performance compared with the parent zeolite. ${ }^{[24,26]}$ Tsapatsis et al. ${ }^{[27]}$ described swelling of high silica MCM-22P using similar surfactant/TPA-OH mixture at room temperature, however, it was not equally effective for MCM-22P with higher Al content. ${ }^{[28]}$ As a further fundamental step, Corma and co-workers ${ }^{[12,29]}$ used ultrasonication of the previous swollen material to produce delaminated zeolite (ITQ-2). ITQ-2 contains exfoliated single crystalline layers with the layer structure of MCM-22P and surface areas up to $900 \mathrm{~m}^{2} / \mathrm{g}$. Recently, the delamination of layered zeolite precursor and synthesis of UCB1 under milder conditions $(\mathrm{pH} 9)$ in aqueous solution was reported. $^{[30]}$

Most zeolite precursors are formed as multi-layer stacks of one or one-half unit cell thick mono-layers having appropriate zeolite structure. The layers are usually separated by organic template layers or domains, often with extensive hydrogen bonding throughout the crystal. ${ }^{[31]}$ The transformation to ordered zeolite frameworks can occur upon removal of the template and bridging of the layers by topotactic condensation. ${ }^{[17]}$ Alternatively, different lamellar, delaminated, pillared, stabilized and other forms can be obtained by post-synthesis treatments. ${ }^{[19]}$ The transformation of MCM-22P into a variety of materials of MWW family provides the best evidence ${ }^{[18,29]}$ about the possibly unlimited potential in this area.

In addition, completely new way of preparation of twodimensional zeolites (from 3D to 2D) has been discovered with UTL zeolite. The 3D framework can be transformed into 2D lamellar structure, formally a layered zeolite precursor ${ }^{[32]}$ by selective degradation. This gives many additional options how to prepare and further modify zeolite materials by the interplay between 2D and 3D structures.

This contribution concerns the lamellar product formed initially during the synthesis of zeolite TUN (TNU-9) with 1,4-bis(Nmethylpyrrolidinium)butane and $\mathrm{Na}+$ ions as structure-directing agents. ${ }^{[21]}$ This lamellar transient product (vide infra) recrystallizes into TUN but its structure appears to be more like to MCM-22P. Specifically, the XRD pattern suggests the presence of stacked MWW layers but without lateral order (not in-register) and is therefore related to EMM-10P. ${ }^{[33]}$

The formation of MWW type intermediate phase during synthesis of TUN was reported previously but with another template, $\mathrm{N}, \mathrm{N}, \mathrm{N}, \mathrm{N}^{\circ}, \mathrm{N}^{\star}, \mathrm{N}^{6}$-hexamethyl-pentanediammonium. ${ }^{[34]}$ That product was also similar to EMM-10P but not explored in detail, especially with regard to its further modifications as layered zeolites for example swelling/pillaring. Such transformations of the disordered MWW precursors have not been reported before and undertaken in this study to compare with their ordered counterpart MCM-22P. Previously, only the latter was demonstrated to be swellable. The mis-aligned stacking in IPC-3P, EMM-10P and related MWW materials (vide supra) is often observed with di-quaternary ammonium templates and warrants closer study in particular for comparison with the ordered MCM-22P. The disordered MWW precursor EMM-10P was claimed to be swellable but no further evidence was presented. ${ }^{[33]}$

The focus of the present publication is to verify identity of the apparent layered zeolite precursor forming during crystallization of TUN zeolite, to explore the potential for its swelling and pillaring, and to compare with the ordered counterpart MCM-22P. The following nomenclature has been adopted for individual materials described here: IPC-3P (P-precursor, IPC stands for Institute of Physical Chemistry) intermediate material obtained during the preparation of TUN at shorter synthesis times and possessing lamellar structure, IPC-3 - calcined form of ICP-3P, IPC-3SW - swollen material obtained from ICP-3P by surfactant intercalation, IPC-3PI pillared material.

\section{Results and Discussion}

This publication has two goals mentioned in the introduction: (i) detailed structural identification of the layered zeolite intermediate, IPC-3P, forming during the synthesis of TUN zeolite and (ii) investigation of its swelling/pillaring potential. As for post-synthesis generation of expanded (i.e. swollen/pillared) derivatives it cannot be taken for granted based on apparent similarity to MCM-22P. For example, one might think it possible for the diquaternary template like the one employed here to crosslink or span layers hindering expansion by intercalation. The discussion of the results is presented according to characterization method.

Synthesis and X-ray powder diffraction: The primary product, layered IPC-3P, was isolated as an intermediate during the synthesis of TUN zeolite with initial gel $\mathrm{Si} / \mathrm{Al} \sim 30$ after crystallization for 5 days at $160{ }^{\circ} \mathrm{C}$. The $\mathrm{Si} / \mathrm{Al}$ of IPC-3P was 26.6 determined by X-ray fluorescence while that of the final TUN product was 16.3. This behavior represents the Ostwald rule of successive transformations ${ }^{[35]}$ and is consistent with increasing frameworks densities of MWW (15.9) and TUN (17.6).

XRD patterns of the layered precursor (IPC-3P), its calcined (IPC-3) and swollen (IPC-3SW) forms are shown in Figure 1. For comparison, XRD patterns of MCM-22P and swollen MCM-22SW are included.

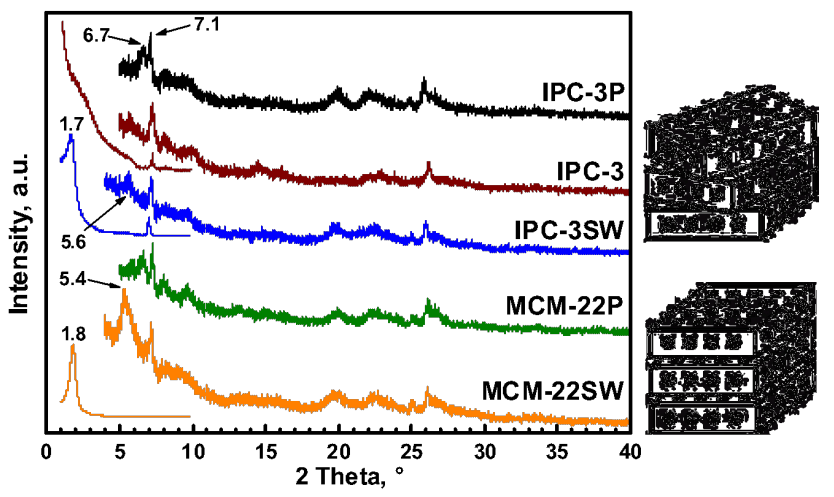

Figure 1. XRD patterns of as-made (IPC-3P), calcined (IPC-3) and swollen (IPC-3SW) samples in comparison with MCM-22P and its swollen (MCM-22SW) form. The presumed layered structure of MCM-22P and IPC-3P are shown on the right. 
The XRD profiles of IPC-3P and its derivatives comprise mainly diffuse and ill-defined maxima that prevent direct structure identification by standard approaches, i.e. based on peak positions and unit cell. However, on the basis of position and relative intensities of several relatively sharp maxima IPC-3P is identified as containing MWW layers with expanded stacking repeat $\sim 2.6 \mathrm{~nm}$ indicated by the peak at ca. $6.7^{\circ} 2 \Theta$ (interlayer reflection (002)). $[18,33,36]$ In detail, all products in Figure 1 show relatively sharp and well defined maxima at $7.1,25.5$ and $26^{\circ} 2 \Theta$, corresponding to the (100), (220) and (310) reflections of the MWW layers. The additional tell-tale feature is the broad band between $8-10^{\circ}$ that proves disordered stacking of the MWW layers in IPC-3P like in EMM-10P and MCM-56. ${ }^{[33]}$ Simultaneously this distinguishes the material from MCM-22P in which the MWW layers are aligned vertically i.e. the structure is ordered. The distinct trough in the calcined IPC-3 sample at $\sim 9^{\circ}$ is an indication that some of the layer stacking becomes ordered upon calcination. When the structure contracts upon calcination and silanols from opposite layers condense, some of the layers remain in lateral disorder while some apparently re-orient slightly and condense congruently, i.e. in alignment. Similar observations were confirmed for EMM-10P using electron diffraction. ${ }^{[33]}$ After calcination, the diffraction lines at around $6.5^{\circ}$ are absent because of the change in crystallographic repeat to ca. $2.5 \mathrm{~nm}$ causing its shift of the (002) reflection and merging with the prominent intra-layer (100) peak at around $7.1^{\circ}$ The differences between XRD patterns of the related ordered pair MCM-22P and MCM-22 could be explained by the formation of SiO-Si linkages between the layers upon calcination ${ }^{[38,39]}$ and resultant periodic 3-D structure. The patterns of as-made (IPC-3P) and calcined (IPC-3) material indicate contraction in the layer stacking direction of around 0.1-0.2 nm but preservation of lateral disorder leaves uncertainty regarding the geometry of interlayer linking. These initial conclusions about the structure of IPC-3P are further validated by $\mathrm{XRD}$ characteristics and electron microscopic characterization. The BET values for IPC-3 and the swollen calcined material in Table 1 indicate high, possibly fully crystalline nature of these products.

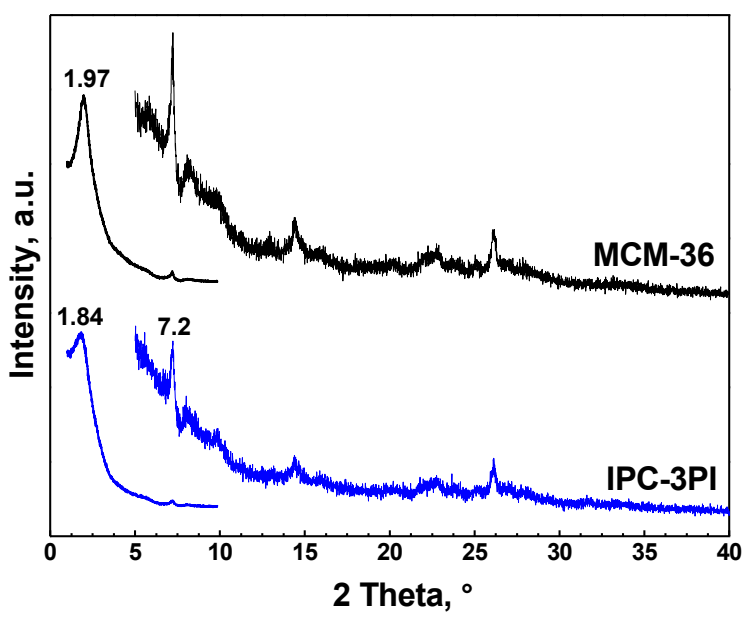

Figure 2. XRD patterns of the pillared IPC-3 sample and the comparison with MCM-36.

The XRD pattern of the IPC-3P swollen sample (IPC-3SW) shown in Figure 1 is consistent with high degree of swelling ${ }^{[18,19,25]}$. In particular, the (002) reflection of IPC-3P at $6.7^{\circ}$ disappears and a new interlayer peak is seen at low angle below $2^{\circ}$, which is typical for swollen materials and indicates an increase in layer spacing to approximately $5 \mathrm{~nm}$. The specific position at $2 \Theta=1.7^{\circ}$ corresponds to $d$-spacing $5.2 \mathrm{~nm}$. The reflection at around $2 \Theta=5.4^{\circ}$ can be a $(003)$ reflection ${ }^{[27]}$ and has been recognized ${ }^{[25]}$ as necessary evidence of efficient swelling of MWW structure. Further evaluation of the swelling is based on the pillared derivative.

XRD patterns of pillared IPC-3PI sample and that of MCM-36 prepared after swelling of the layered MCM-22P with CTMA-OH and pillared according to Refs. ${ }^{[25,40]}$ are shown in Figure 2. The patterns are qualitatively similar in the range of $2-\Theta 5-40^{\circ}$, and the observed diffraction lines are in agreement with those of MCM-36 reported in the Ref. ${ }^{[25]}$ In the low angle region the inter-layer (001) peak is located below $2^{\circ} 2 \Theta$. The differences in position indicate slight variation in interlayer spacing while intensities reflect efficiency of swelling/pillaring.

SEM and HRTEM microscopy: SEM images of the prepared layered IPC-3P precursor (Figure 3A) shows aggregates of thin plate-like crystals. The diameter of IPC-3P crystals is about $1 \mu \mathrm{m}$ with thickness of $\sim 0.1 \mu \mathrm{m}$, i.e. corresponding to stacking of approximately four MWW mono-layers. These results are similar to those reported by Tsapatsis et al. ${ }^{[27]}$ and Chlubná and coworkers ${ }^{[40]}$.
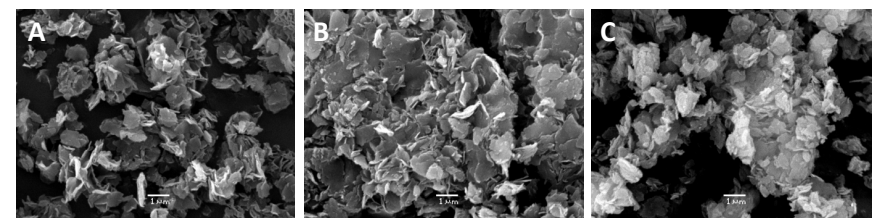

Figure 3. SEM images of prepared IPC-3P (A), IPC-3SW (B) and IPC-3PI (C).

Swelling with CTMA-OH at room temperature (Figure 3B) and subsequent pillaring treatment at $85{ }^{\circ} \mathrm{C}$ (Figure 3C) did not result in any significant changes in crystal morphology. The particles appeared in SEM as large aggregates of thin rounded flakes roughly of $1 \mu \mathrm{m}$ in diameter.

High resolution transmission electron microscopy (HRTEM) studies were performed to investigate the microstructures of the zeolite plates and to verify that IPC-3P was successfully transformed into very thin zeolite layers after the swelling with CTMA/surfactant molecules followed by pillaring treatment with TEOS (Figure 4). Similar to many other zeolites, the microplates were easily damaged and therefore decomposed within a few seconds under the electron beam before HRTEM images could be attained. Previously, HRTEM images of beam sensitive materials such as zeolites, MOFs and $\mathrm{C}_{60} /$ trimethylbenzene composites have been achieved by carrying out several sample treat-ments including dehydrating, electron beam annealing and applying a low-dose electron beam. ${ }^{[41,42,43]}$ Using the latter technique it was possible to see crystalline fringes along the short axis of the IPC-3P plates with $d$-spacings of $1.26 \mathrm{~nm}$ (marked A in Figure 4A). This corresponds to approximately half the unit cell parameter of MWW. It is also possible to measure crystalline fringes with lower $d$ spacings of $0.40 \mathrm{~nm}$ (marked B in Figure 4A).

Low magnification TEM imaging (inset of Figure 4a) found the microplates had thicknesses in the range of 10-15 nm. HRTEM imaging of a IPC-3-P plate (Figure 4b) shows an almost intact single crystalline layer with measurable fringes (marked A and B in Figure $4 \mathrm{~b}$ ), with an angle between the planes of $60^{\circ}$. These data are consistent with a hexagonal plate structure with a crystallographic $a$ axis of $1.37 \mathrm{~nm}$. This indicates that the layers themselves are 
hexagonal in symmetry, with parameters slightly smaller than those seen in the zeolite-MWW structure $(a=1.42081 \mathrm{~nm})$, consistent with the layers being MWW-like, within experimental error. The TEM results are therefore consistent with the XRD experiments, and that the IPC-3P layers are likely to be closely related to the MWW precursor.
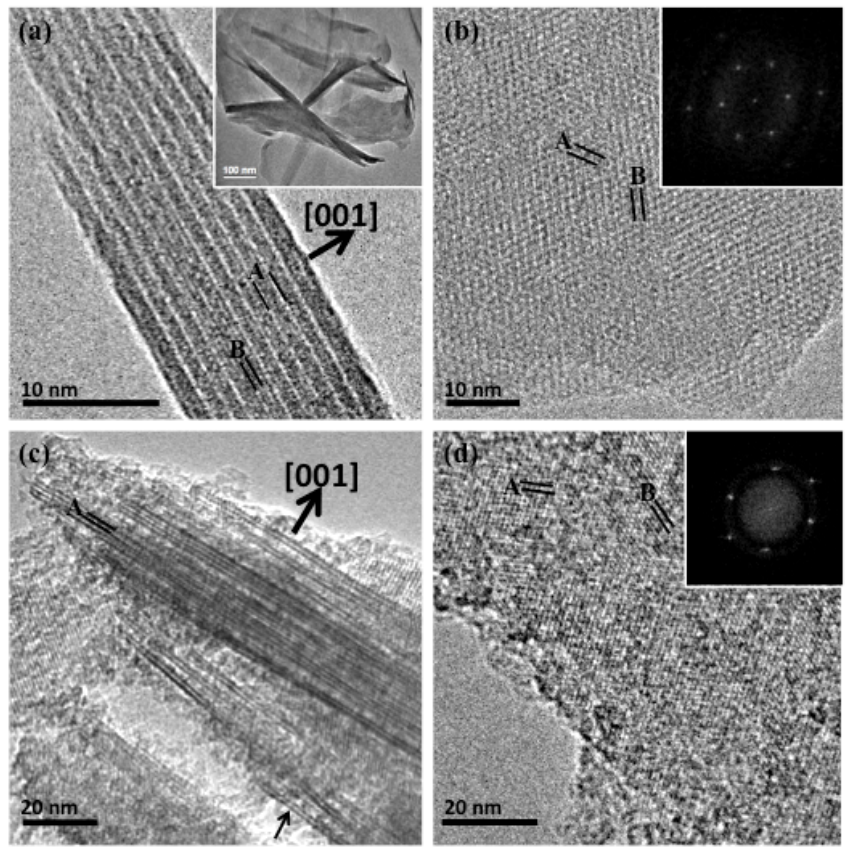

Figure 4. HRTEM images of (a,b) IPC-3P and (c,d) IPC-3PI. (a) HRTEM profile image of an IPC-3P thin plate, showing crystal fringes marked (A) and (B) measuring $1.26 \mathrm{~nm}$ and $0.40 \mathrm{~nm}$ respectively. The low magnification TEM image (inset) shows thin zeolite plates with thicknesses in the range of 10-15 nm. (b) HRTEM image and corresponding FFT pattern (inset) showing crystalline fringes (A) and (B) consistent with a hexagonal structure (c) HRTEM image of pillared IPC-3PI expanded along the [001] direction. The smallest $d$-spacing marked (A) was measured as $1.20 \mathrm{~nm}$. Some very thin plates (marked by black arrow) have thicknesses corresponding to approximately one unit cell. (d) HRTEM image and FFT pattern (inset) from IPC-3-PI plates viewed down axis showing the thin zeolite plates remain intact. Crystalline fringes marked A and B were measured as $1.07 \mathrm{~nm}$ and $0.86 \mathrm{~nm}$..

SEM imaging found no significant difference to the morphology of the microplates after swelling and subsequent pillaring treatment. HRTEM images revealed that the layered component is maintained. Crystalline fringes perpendicular to the short axis of the IPC-3PI plates measured $1.20 \mathrm{~nm}$.(Figure 4c A). Some IPC-3PI plates were noted to be as thin as one unit cell (marked by black arrow in Figure 4c), and separated from each other. The observed layer separations indicate an expansion of the material, and are consistent with the existence of props (pillars) between the layers. In some regions plates had thicknesses of up to $\sim 10 \mathrm{~nm}$ ( 4 unit cells) suggesting absence of pillars and so less than complete swelling/pillaring. The HRTEM image in Figure 4d recorded from viewing the IPC-3PI plates indicates that the layers retain their crystalline nature, but some defects have been detected. Examination of several HRTEM images show that for a more accurate indexing the hexagonal unit cell parameter is reduced slightly $(\mathrm{a}=1.23 \mathrm{~nm})$ compared to the IPC-3P. The HRTEM images in Figure 4d agree well with the microplate structures viewed by SEM in Figures 3a and $3 \mathrm{c}$ and the interlayer spacing calculated from the broad peak observed at $1.84^{\circ}$ in the XRD pattern of IPC-3PI (Figure 2).
Nitrogen adsorption: Nitrogen adsorption isotherms provide valuable information about the completeness of swelling and pillaring because X-ray diffraction allows only qualitative evaluation due to mostly broad and diffuse diffraction maxima. BET surface area was evaluated using adsorption data in the range of a relative pressure from $\mathrm{p} / \mathrm{p}_{0}=0.05$ to $\mathrm{p} / \mathrm{p}_{0}=0.20$. The $t$-plot method ${ }^{[44]}$ was applied to determine the volume of micropores $\left(\mathrm{V}_{\mathrm{mic}}\right)$. The volume of larger mesopores $\left(\mathrm{V}_{\text {mesol }}\right)$ with broad distribution from 5 to $20 \mathrm{~nm}$ was calculated from the desorption branch of the isotherm using BJH method ${ }^{[45]}$ DFT algorithm (using standard Micromeritics software for slit-shape pores) revealed the presence of smaller mesopores $\left(\mathrm{V}_{\text {meso2 }},<5 \mathrm{~nm}\right.$ in diameter) for the pillared samples. The amount of adsorbed sorbate at $\mathrm{p} / \mathrm{p}_{0}=0.97$ was used to represent the total adsorption capacity $\left(\mathrm{V}_{\text {tot }}\right)$. The values of determined textural properties, including those for MWW and MCM-36 for comparison are summarized in Table 1.

Table 1. Textural properties of zeolite TUN, IPC-3 derivatives and relevant MWW materials

\begin{tabular}{|c|c|c|c|c|c|c|}
\hline Sample & $\begin{array}{l}\text { BET } \\
{\left[\mathrm{m}^{2} / \mathrm{g}\right]}\end{array}$ & $\begin{array}{l}\mathrm{V}_{\text {mic }}^{[\mathrm{a}]} \\
{\left[\mathrm{cm}^{3} / \mathrm{g}\right]}\end{array}$ & $\begin{array}{l}V_{\text {int }}^{[b]} \\
{\left[\mathrm{cm}^{3} / \mathrm{g}\right]}\end{array}$ & $\begin{array}{l}\mathrm{V}_{\text {mesol }}{ }^{\mathrm{b}]} \\
{\left[\mathrm{cm}^{3} / \mathrm{g}\right]}\end{array}$ & $\begin{array}{l}\mathrm{V}_{\text {meso2 }}{ }^{[\mathrm{c}]} \\
{\left[\mathrm{cm}^{3} / \mathrm{g}\right]}\end{array}$ & $\begin{array}{l}V_{\text {tot }}^{[\mathrm{d}]} \\
{\left[\mathrm{cm}^{3} / \mathrm{g}\right]}\end{array}$ \\
\hline TNU-9 & 381 & 0.167 & - & - & - & 0.193 \\
\hline IPC-3 & 475 & 0.146 & 0.247 & - & - & 0.406 \\
\hline MWW & 477 & 0.170 & - & - & - & 0.425 \\
\hline IPC-3SW & 451 & 0.131 & 0.338 & - & - & 0.481 \\
\hline MCM-36 & 637 & 0.090 & - & 0.221 & 0.111 & 0.450 \\
\hline IPC-3PI & 682 & 0.069 & - & 0.313 & 0.126 & 0.572 \\
\hline
\end{tabular}

[a] $t$-plot method. [b] BJH method. [c] DFT method. [d] at $\mathrm{p} / \mathrm{p}_{0}=0.97$.

Nitrogen adsorption isotherms for TUN zeolite (Figure 5a), the calcined intermediate IPC-3 and swollen calcined IPC-3SW are typical for microporous materials of the type I according to the IUPAC classification. ${ }^{[46]}$ Their BET surface area values and the micropore volumes agree well with the literature data. ${ }^{[21]}$ For IPC-3 (Figure 5b) and IPC-3SW (swollen product, calcined - Figure 5c) the hysteresis loop observed at higher relative pressures can be attributed to the interparticle adsorption. Calcination of swollen IPC-3SW represents a highly desirable control test for the veracity of swelling of zeolite precursors since removal of the intercalated surfactant is expected to result in return to the original layered structure (in calcined form). If the swelling procedure carried out at high $\mathrm{pH}$ generated undesired mesoporous contaminants, they may be detectable in the calcined swollen materials. The corresponding values found in Table 1 indicate slight decrease compared with starting IPC-3P but are not considered significant and suggest the absence of mesoporous impurities.

The pillared sample IPC-3PI exhibits enhanced BET surface area and mesopore volumes (Figure $5 \mathrm{f}$ ). The volume adsorbed up to $\mathrm{p} / \mathrm{p}_{0} \sim 0.45$ is almost doubled compared with the original zeolite IPC-3 and the uptake profile indicates that mesopore structure is created by pillaring. The pillared material also exhibits reduced micropore volume, $0.069 \mathrm{~cm}^{3} / \mathrm{g}$, which is expected in such cases, (Table 1). Overall the changes in the micro- and mesopore characteristics reflect the expected structural changes caused by formation of pillars that make permanent separation between the individual layers of the order of $2 \mathrm{~nm}$. 
Nitrogen adsorption isotherms for MWW (Figure 5d) and MCM-36 (Figure 5e) with their respective textural characteristics shown in Table 1 are comparable with those in Ref., ${ }^{[40]}$ they are slightly lower than for MCM-36 $\left(800-950 \mathrm{~m}^{2} / \mathrm{g}\right)$ reported in the work of Tsapatsis et al. ${ }^{[27]}$ and Corma et al. ${ }^{[47]}$

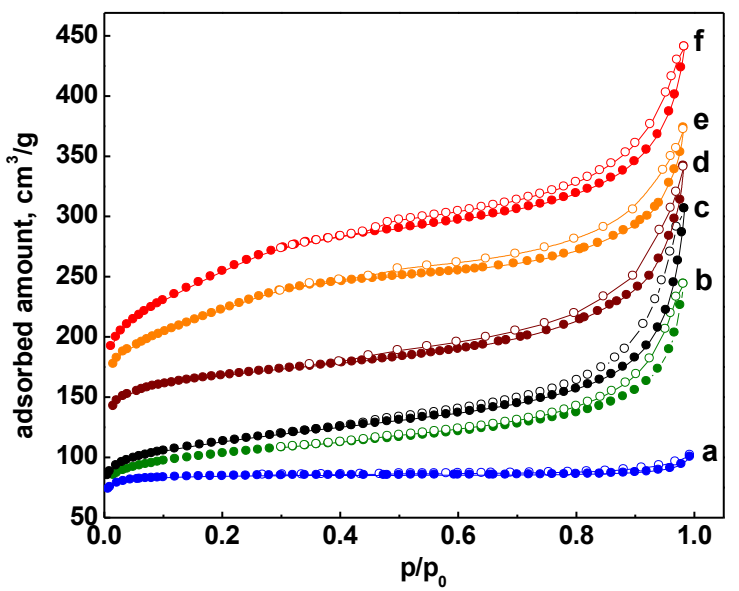

Figure 5. Nitrogen adsorption $(\bullet$ ) and desorption (o) isotherms of TNU-9 (a), IPC-3 (b) IPC-3SW (c), MCM-22 (d), MCM-36 (e) and IPC-3PI (f). For better view, the following isotherms were shifted along y axis (in $\mathrm{cm} 3 / \mathrm{g}$ ): MCM-22 (d, overlap with IPC-3) +60, MCM-36 (e) +30, IPC-3PI (f, partial overlap with MCM-36) +60

FTIR - silanol content and acidity characterization: Standard FTIR methodology was used to characterize silanol content and acid sites upon adsorption of pyridine and 2,6-di-tert-butylpyridine (DTBP). Total concentration of Lewis $\left(\mathrm{C}_{\mathrm{L}}\right)$ and Brønsted $\left(\mathrm{C}_{\mathrm{B}}\right)$ acid sites is obtained by adsorption of pyridine while Brønsted sites on internal and external surface are titrated based on DTBP adsorption. The IR spectra of IPC-3 in comparison with IPC-3PI and TUN zeolite are shown in Figures 6A,B while those of MCM-22 and MCM36 are depicted in Figures 6C,D. In the region of hydroxyl vibrations (Figures 6A,C) two main absorption bands were found. The sharp absorption band with the maximum intensity around $3745 \mathrm{~cm}^{-1}$ belongs to terminal silanol groups exposed at the external surface; the second broader band with a maximum at $3621 \mathrm{~cm}^{-1}$ is due to bridging acid Si-OH-Al groups. ${ }^{[48]}$ A very weak absorption band around $3670 \mathrm{~cm}^{-1}$ being characteristic for $\mathrm{OH}$ groups located on extra-framework alumina was found in IPC-3. Such a band is usually present in high silica zeolites or ultra-stabilized zeolites and is characteristic of Al-OH vibrations. ${ }^{[49]}$

All samples show abundant silanol content visibly increasing in the order TUN $>$ IPC-3 $>$ MWW $>$ IPC-3PI. The smaller value for IPC-3 compared to MWW may reflect larger crystals size. Pillared materials show the highest content of silanols as expected from increased exposure of zeolite surfaces and simultaneously due to silica present as the pillars. Upon adsorption of pyridine all bands due to hydroxyls disappear indicating the accessibility of all Brønsted acid sites in all studied samples for pyridine. The intensity of the band from $\mathrm{OH}$ groups located on extra-framework alumina species (IPC-3, $3670 \mathrm{~cm}^{-1}$ ) decreased slightly after pyridine adsorption at $150^{\circ} \mathrm{C}$.

In the region of pyridine vibrations (Figure 6B), new bands of pyridine interacting with Brønsted and Lewis acid sites appeared after pyridine adsorption. The absorption band at $1454 \mathrm{~cm}^{-1}$ is characteristic for pyridine interacting with Lewis acid sites, while the band at $1545 \mathrm{~cm}^{-1}$ reflects adsorption of pyridine on Brønsted acid sites. ${ }^{[50]}$ The intense absorption band around $1490 \mathrm{~cm}^{-1}$ is due to vibrations of pyridinium ions and coordinatively adsorbed pyridine ${ }^{[51]}$ The determined concentrations of Brønsted and Lewis acids sites are given in Table 2. Also included are results for high (A1)MWW and MCM-36 published previously. ${ }^{[40]}$ Zeolite TUN and high (Al)MWW and MCM-36 show high relative content of Brønsted acid sites compared with Lewis ones, i.e. 3-4 to 1. More siliceous IPC-3, MWW with comparable Si/Al and their pillared derivatives have similar concentration ratio of the both types of acid sites, the highest being approximately 2 for MWW. Upon pillaring, there is up to $50 \%$ reduction in the concentration of Brønsted acid sites but not much of Lewis. The former is understandable based on dilution caused by insertion of inert silica pillars

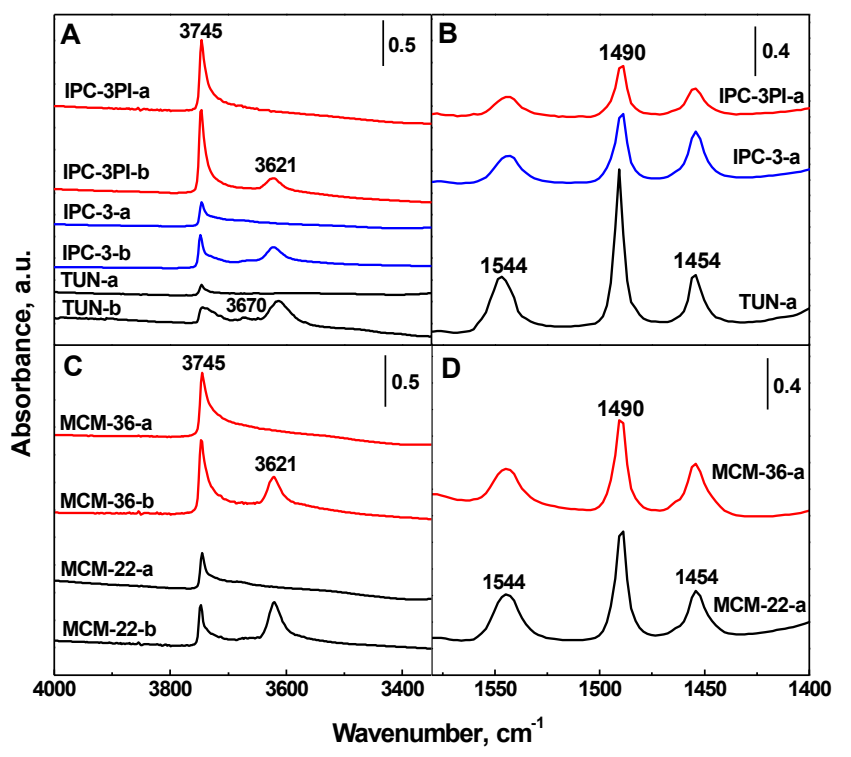

Figure 6. IR spectra of TUN, IPC-3 and IPC-3PI (A, B) and the comparison with MWW and MCM-36 (C, D); region of hydroxyl vibration (A, C); region of pyridine vibration (B, D). Before (b) and after (a) adsorption of pyridine.

Table 2. Lewis and Brønsted acid sites concentrations

\begin{tabular}{llllll}
\hline Sample $^{[\mathrm{a}]}$ & $\mathrm{Si} / \mathrm{Al}^{[\mathrm{b}]}$ & $\begin{array}{l}\mathrm{C}_{\mathrm{B}} \\
{[\mathrm{mmol} / \mathrm{g}]}\end{array}$ & $\begin{array}{l}\mathrm{C}_{\mathrm{L}} \\
{[\mathrm{mmol} / \mathrm{g}]}\end{array}$ & $\begin{array}{l}\mathrm{C}_{\mathrm{B}}{ }^{[\mathrm{c}]} \\
{[\mathrm{mmol} / \mathrm{g}]}\end{array}$ & $\mathrm{Si} / \mathrm{Al}^{[\mathrm{d}]}$ \\
\hline TNU-9 & 19.8 & 0.49 & 0.16 & - & 16.3 \\
IPC-3 & 23.5 & 0.26 & 0.21 & 0.021 & 26.6 \\
IPC-3-PI & 38.3 & 0.13 & 0.14 & 0.066 & 35.9 \\
MCM-22 & 24.6 & 0.33 & 0.17 & - & - \\
MCM-36 & 29.9 & 0.20 & 0.17 & n.d. & - \\
MCM-22 $^{[\mathrm{e}]}$ & 13.5 & 0.78 & 0.18 & 0.04 & - \\
MCM-36 $^{[\mathrm{e}]}$ & 28.7 & 0.38 & 0.09 & 0.07 & -
\end{tabular}

[a] IR experiments performed at $150^{\circ} \mathrm{C}$. [b] determined from IR. [c] adsorption of 2,6DTBP. [d] chemical analysis. [e] taken from Ref. [40].

The concentration of acid sites located on the individual layers of IPC-3 was evaluated using 2,6-di-tert-butyl-pyridine (DTBP) as a large-size probe molecule that cannot access micropores. In comparison with the adsorption of pyridine, no substantial differences in the shape and intensity of absorption bands of 
hydroxyl vibrations were observed for IPC-3 and IPC-3-PI sample after activation at $450{ }^{\circ} \mathrm{C}$. After the adsorption of DTBP, the intensity of silanol groups slightly decreased (14\% for IPC-3 and $8 \%$ for IPC-3PI, Figure 7A). In the region of DTBP vibrations, the absorption band at $1535 \mathrm{~cm}^{-1}$ is typical for DTBP interacting with Brønsted acid sites. The absence of a band at $1545 \mathrm{~cm}^{-1}$ confirms no dealkylation of the probe molecule (Figure 7B).

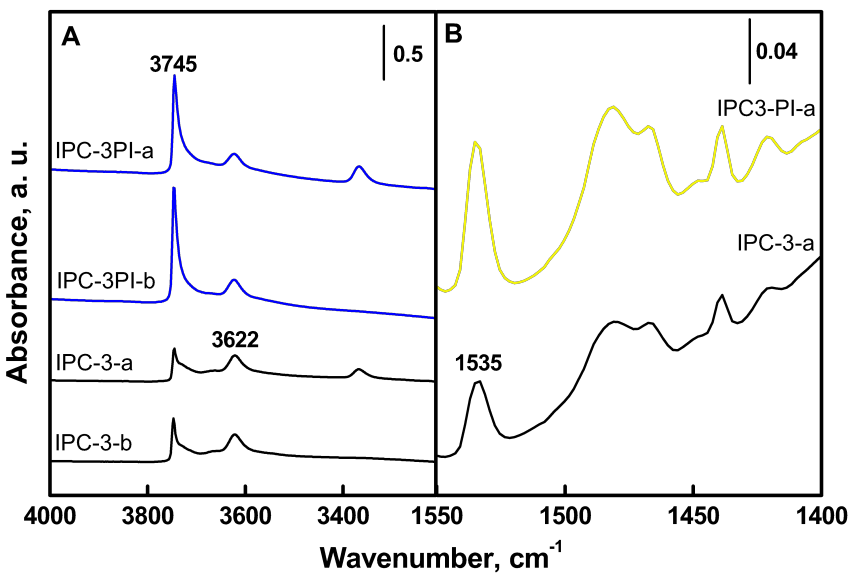

Figure 7. IR spectra of IPC-3 and its pillared form. Region of hydroxyl vibration (A), region of 2,6-DTBP vibration (B). Before (b) and after (a) adsorption.

The concentration of Brønsted acid sites accessible to DTPB on IPC-3 was $0.021 \mathrm{mmol} / \mathrm{g}$, this value represents $8 \%$ of the total amount of this type of acid sites. The increased uptake of DTBP by 3 times upon swelling and pillaring $(0.021$ vs. $0.066 \mathrm{mmol} / \mathrm{g}$ for IPC-3PI) indicates enhanced accessibility of acid sites for bulky probe molecules. This accompanies the increase in the BET area from 451 to $683 \mathrm{~m}^{2} / \mathrm{g}$ for IPC-3 and pillared IPC-3 materials and provides promising catalyst for consideration (Table 1 ). After the pillaring treatment, 2/3 of the total amount of Brønsted acid sites is located on the external surface. In contrast no detectable acid sites were located on the external surface of TUN zeolite. For MWW, the calculated concentration of acid sites exposed to the outer surface was $0.04 \mathrm{mmol} / \mathrm{g} ;{ }^{[40]}$ the value higher than of IPC-3, but presenting only $5 \%$ of the total amount of Brønsted acid sites.

The IPC-3 zeolite family and other disordered $M W W$ layered precursors: The present work confirmed that IPC-1P is a layered precursor related to MWW framework. In contrast to the similar but ordered MCM-22P the layers in IPC-3P are not vertically aligned according to XRD evidence. Similar to MCM-22P, the present IPC$3 \mathrm{P}$ is shown to be swellable and further produce the pillared zeolite similar if not identical to MCM-36. By analogy to MWW we can refer to IPC-3P and its derivatives as a zeolite family or rather subfamily of MWW zeolites.

There are in fact several other materials related to IPC-3P i.e. multi-layer crystals of MWW monolayers misaligned laterally. They are often referred to in the literature as being MWW or related but the distinction from the ordered MCM-22P is not explicitly invoked as it was made for EMM-10P. ${ }^{[33]}$ These materials may include, in addition to the latter HM-MWW (hexamethonium templated MCM22), ITQ-30 and UZM-8. ${ }^{[52-54]}$

This conclusion is tentative and based mainly on the features found in the XRD that are similar to EMM-10P, especially between
6 and $10^{\circ} 2-\Theta$. Potential differences and their possible significance may be resolved in the future.

\section{Conclusion}

The identification of the layered intermediate obtained during the synthesis of TUN zeolite, IPC-3P, as a material similar to MCM$22 \mathrm{P}$ has been presented. However, there is a significant difference in the ordering of layers relative to each other in IPC-3P when compared to MCM-22P. This difference in overall structure could be of significant relevance in determining the overall pathway of the zeolite synthesis, and in determining the final zeolite product. We have also shown that IPC-3P is susceptible to swelling using CTMA-OH. The swollen material was converted into pillared product (IPC-3PI) based on standard treatment with TEOS. X-ray diffraction, nitrogen sorption and FTIR spectroscopy were used for detailed characterization. The prepared pillared sample exhibits increase in textural parameters compared to the parent zeolite (BET 475 vs. $682 \mathrm{~m}^{2} / \mathrm{g}$ ) suggesting highly efficient swelling and further pillaring. This is consistent with features in the XRD pattern, where new interlayer peak is seen at low angle below $2^{\circ}$, being typical for swollen/pillared materials and indicates an increase in the layer spacing to approximately $5 \mathrm{~nm}$.

IR spectroscopy revealed the decrease in the concentration of Brønsted (from 0.26 to $0.13 \mathrm{mmol} / \mathrm{g}$ ) and Lewis (from 0.21 to $0.14 \mathrm{mmol} / \mathrm{g}$ ) acid sites when compared with the starting calcined IPC-3 material due to the introduction of inert silica pillars. Although the properties of swollen and pillared form of IPC-3P materials are little bit different than those for MCM-36 analogue, the structural properties are similar as for the MCM-22P based on the detailed characterization by HRTEM. HRTEM images revealed that the layered component is maintained and agree well with the microplate structures viewed by SEM.

\section{Experimental Section}

Synthesis of IPC-3P: The synthesis of IPC-3P was based on the procedure described in the Ref. ${ }^{[21]}$ The organic SDA cation 1,4-bis(N-methylpyrrolidinium)butane (1,4-MPB) was prepared, purified and characterized according to the literature ${ }^{[37]}$ The final molar gel composition was: $4.5(1,4-\mathrm{MPB}): 11 \mathrm{Na}_{2} \mathrm{O}: 0.5 \mathrm{Al}_{2} \mathrm{O}_{3}: 30 \mathrm{SiO}_{2}: 1200 \mathrm{H}_{2} \mathrm{O}$. The mixture was stirred at room temperature for 1 day. The synthesis was performed in $500-\mathrm{mL}$ Teflon-lined stainless steel autoclave heated at $160{ }^{\circ} \mathrm{C}$ under agitation and autogenous pressure for 5 days. The solid product was filtered off, washed out with excess of distilled water and dried in the oven at $80^{\circ} \mathrm{C}$ overnight. This sample is denoted IPC-3P. Swelling: Swelling was performed in 100-mL flask in which $3 \mathrm{~g}$ of dried IPC-3P was mixed with $60 \mathrm{~mL}$ of cetyl trimethyl ammonium hydroxide (CTMA-OH, obtained by ion exchange with AG1-X8 resin, BioRad) and the solution was stirred for $24 \mathrm{~h}$ at room temperature. After swelling, the mixture was centrifuged for $15 \mathrm{~min}$ followed by threefold washing with distilled water and centrifugation for another $15 \mathrm{~min}$. Finally, the solids were dried overnight in the oven at $60{ }^{\circ} \mathrm{C}$. The obtained dried sample was denoted IPC-3SW.

Pillaring: The swollen material was treated with tetraethyl orthosilicate (TEOS, $98 \%$, Aldrich) for $18 \mathrm{~h}$ at $85^{\circ} \mathrm{C}$ under reflux using $30 \mathrm{~mL}$ of TEOS per $1 \mathrm{~g}$ of the swollen sample. The solids were separated by centrifugation and dried in air at $40{ }^{\circ} \mathrm{C}$ overnight. To ensure complete hydrolysis of TEOS, the powder was treated with water $(200 \mathrm{~mL} / 1 \mathrm{~g}$ of the sample) and stirred for 1 day. The product was centrifuged again, washed with water and dried at $60^{\circ} \mathrm{C}$. The obtained material were marked IPC-3PI

Calcination, ion-exchange: Both parent and treated samples were calcined in a stream of air at $540{ }^{\circ} \mathrm{C}$ for $8 \mathrm{~h}$ with a heating rate $1{ }^{\circ} \mathrm{C} / \mathrm{min}$. Calcined samples were then treated four-times with $1 \mathrm{M} \mathrm{NH}_{4} \mathrm{NO}_{3}$ solution $(99 \%$, Lach-Ner) for $4 \mathrm{~h}$ at room temperature using $100 \mathrm{~mL}$ of solution per $1 \mathrm{~g}$ of sample.

Characterization: The structure and crystallinity of all samples was examined by X-ray powder diffraction (XRD) using a Bruker AXS D8 Advance diffractometer equipped with a graphite monochromator and a position sensitive detector Våntec-1 using $\mathrm{CuK} \alpha$ radiation in Bragg-Brentano geometry. The size and shape of zeolite crystals were 
examined by scanning electron microscopy (SEM) on a JEOL, JSM-5500LV microscope. For the measurement, crystals were coated with a thin platinum layer by sputtering in vacuum chamber of a BAL-TEC SCD-050. The microstructures were investigated using high resolution transmission electron microscopy (HRTEM) on a Jeol JEM-2011 electron microscope operating at an accelerating voltage of $200 \mathrm{kV}$. The Jeol JEM-2011 electron microscope is equipped with an Oxford Link ISIS SemiSTEM EDX system, which was used for confirming chemical compositions of the samples. The HRTEM images were recorded using a Gatan 794 CCD camera. The camera length, sample position and magnification were calibrated using standard gold film methods.

Concentration of Lewis (L) and Brønsted (B) acid sites was determined from adsorption of pyridine (PYR) followed by FTIR spectroscopy (Nicolet Protégé 460 Magna). The individual samples were pressed into self-supporting wafers with a density of 8.0 $12 \mathrm{mg} / \mathrm{cm}^{2}$ and activated at $450{ }^{\circ} \mathrm{C}$ overnight. Before adsorption, pyridine was outgassed by freezing and thawing cycles. Pyridine adsorption was carried out at $150{ }^{\circ} \mathrm{C}$ for $20 \mathrm{~min}$ at partial pressure $500-600 \mathrm{~Pa}$, followed by desorption for $15 \mathrm{~min}$. All spectra were recorded with a resolution of $2 \mathrm{~cm}^{-1}$ by collecting 128 scans for a single spectrum. Spectra were recalculated to a wafer density of $10 \mathrm{mg} / \mathrm{cm}^{2}$. Concentrations of Lewis and Brønsted acid sites were determined from the integral intensities of bands at $1454 \mathrm{~cm}^{-1}$ (Lewis) and at $1545 \mathrm{~cm}^{-1}$ (Brønsted acid sites) using extinction coefficients $\varepsilon(\mathrm{L})=2.22 \mathrm{~cm} / \mu \mathrm{mol}$, and $\varepsilon(\mathrm{B})=1.67 \mathrm{~cm} / \mu \mathrm{mol} .{ }^{[50]}$ The adsorption of 2,6-di-tert-butylpyridine (DTBP) was carried out at $150^{\circ} \mathrm{C}$, and at equilibrium probe vapour pressure with the samples for $15 \mathrm{~min}$. Desorption took place at the same temperature for $1 \mathrm{~h}$ followed by recording of spectra at room temperature. For the quantitative evaluation of the concentration of Lewis and Brønsted acid sites, extinction coefficients for pyridine ${ }^{[50]}$ were used.

Nitrogen sorption isotherms were collected at liquid nitrogen temperature $\left(-196^{\circ} \mathrm{C}\right)$ on a Micromeritics ASAP 2020 volumetric instrument to determine surface area and pore volume of prepared IPC-3 materials. To attain sufficient accuracy in the accumulation of the adsorption data, the ASAP 2020 was equipped with pressure transducers covering the $133 \mathrm{~Pa}, 1.33 \mathrm{kPa}$ and $133 \mathrm{kPa}$ ranges. Prior to the sorption measurements, all samples were outgassed under turbomolecular pump vacuum at $250{ }^{\circ} \mathrm{C}$ for at least $24 \mathrm{~h}$. The chemical composition of zeolites was determined by X-ray fluorescence analysis with a spectrometer Philips PW 1404 using an analytical program UniQuant. The samples were mixed with dentacryl as a binder and pressed on the surface of cellulose pellets.

\section{Acknowledgements}

The authors thank to Dr. Libor Brabec for SEM images and Dr. Arnošt Zukal for nitrogen adsorption measurements. The authors acknowledge the Czech Science Foundation for the support of this research (P106/12/0189). REM is a Royal Society Industry Fellow.

[1] Zeolites and Catalysis: Synthesis, Reactions and Applications, Vol. 1-2 (Eds: J. Čejka, A. Corma, S.I. Zones), WILEY-VCH, Weinheim, 2010.

[2] Introduction to zeolite science and practice, Stud. Surf. Sci. Catal., 3rd Edn., vol. 168 (Eds: J. Čejka, H. van Bekkum, A. Corma, F. Schüth), Elsevier, Amsterdam, 2007.

[3] T. C. Tsai, S. B. Liu, I. Wang, Appl. Catal. A 1999, 181, 355-398.

[4] G. Bellussi, A. Carati, C. Rizzo, R. Millini, Catal. Sci. Technol. 2013, Advance Article, DOI: $10.1039 / \mathrm{C} 2 \mathrm{CY} 20510 \mathrm{~F}$

[5] A. Corma, J. Catal. 2003, 216, 298-312.

[6] M. Bejblová, D. Procházková, J. Čejka, ChemSusChem 2009, 2, 486-499.

[7] D. Kubička, Collect. Czech. Chem. Commun. 2008, 73, 1015-1044.

[8] J. Čejka, G. Centi, J. Perez-Pariente, W.J. Roth, Catal. Today 2012, 179, 2-15.

[9] D. P. Serrano, J. M. Escola, P. Pizarro, Chem. Soc. Rev. 2013, Advance Article, DOI: $10.1039 / \mathrm{C} 2 \mathrm{CS} 35330 \mathrm{~J}$

[10] M. Choi, K. Na, J. Kim, Y. Sakamoto, O. Terasaki, R. Ryoo, Nature 2009, 461 246-249.

[11] L. Bonetto, M. A. Camblor, A. Corma, J. Perez-Pariente, Appl. Catal. A 1992, $82,37-50$

[12] A. Corma, V. Fornes, S. B. Pergher, T. L. M. Maesen, J. G. Burglass, Nature 1998, 396, 353-356

[13] A. Corma, M. J. Diaz-Cabanas, J. Jiang, M. Afeworki, D. L. Dorset, S. L. Soled, K. G. Strohmaier, Proc. Natl. Acad. Sci. U.S.A. 2010, 107, 13997-14002.

[14] C. Martínez, A. Corma, Coord. Chem. Rev. 2011, 255, 1558-1580.

[15] T. Bein, Chem. Mater. 1996, 8, 1636-1653
[16] F. S. O. Ramos, M. K. de Pietre, H. O. Pastore, RSC Adv. 2013, Advance Article, DOI: $10.1039 / \mathrm{C} 2 \mathrm{RA} 21573 \mathrm{~J}$

[17] W. J. Roth, D. L. Dorset, Struct. Chem. 2010, 21, 385-390.

[18] W. J. Roth, D. L. Dorset, Micropor. Mesopor. Mater. 2011, 142, 32-36.

[19] (a) W. J. Roth, J. Čejka, Catal. Sci. Technol. 2011, 1, 43-53, (b) W. J. Roth in Introduction to Zeolite Science and Practice, Vol. 168 (Eds: J. Čejka, H. van Bekkum, A. Corma, F. Schüth), Stud. Surf. Sci. Catal., Elsevier, Amsterdam, 2007, pp. 221-239.

[20] M. K. Rubin, P. Chu, U.S. Patent 4,954,325, 1990

[21] S. B. Hong, H. K. Min, Ch. H. Shin, P. A. Cox, S. J. Warrender, P. A. Wright, J. Am. Chem. Soc. 2007, 129, 10870-10875.

[22] (a) L. Schreyeck, P. Caullet, J. C. Mougenel, J. L. Guth, B. Marler, J. Chem. Soc., Chem. Commun. 1995, 2187-2188, (b) Micropor. Mater. 1996, 6, 259-271.

[23] W. J. Roth, J. C. Vartuli, Stud. Surf. Sci. Catal. 2002, 141, 273-279.

[24] (a) C. T. Kresge, W. J. Roth, U.S. Patent 5,266,541 1993, (b) U.S. Patent $5,278,115,1994$

[25] W. J. Roth, C. T. Kresge, J. C. Vartuli, M. E. Leonowicz, A. S. Fung, S. B. McCullen in Catalysis by Microporous Materials, Vol. 94 (Eds: H. K. Beyer, H. G. Karge, I. Kiricsi, B. Nagy), Stud. Surf. Sci. Catal. Elsevier, New York, 1995, pp. 301-308.

[26] (a) C. T. Kresge, W. J. Roth, K. G. Simmons, J. C. Vartuli, U.S. Patent 5,364,999 1994, (b) U.S. Patent 5,365,000 1994

[27] S. Maheshwari, E. Jordan, S. Kumar, F. S. Bates, R. L. Penn, D. F. Shantz, M. Tsapatsis, J. Am. Chem. Soc. 2008, 130, 1507-1516.

[28] W. J. Roth, P. Chlubná, M. Kubů, D. Vitvarová, Catal. Today 2012, in press, http://dx.doi.org/10.1016/j.cattod.2012.07.040.

[29] A. Corma, V. Fornes, J. Martinez-Triguero, S. B. Pergher, J. Catal. 1999, 186, $57-63$.

[30] I. Ogino, M. M. Nigra, S-J. Hwang, J-M. Ha, T. Rea, S. I. Zones, A. Katz, J. Am. Chem. Soc. 2011, 133, 3288-3291.

[31] L. Grajciar, O. Bludský, W. J. Roth, J. Herman, P. Nachtigall, Catal. Today 2012, in press, http://dx.doi.org/10.1016/j.cattod.2012.07.018.

[32] W. J. Roth, O. V. Shvets, M. Shamzhy, P. Chlubná, M. Kubů, P. Nachtigall, J. Čejka, J. Am. Chem. Soc. 2011, 133, 6130-6133.

[33] W. J. Roth, D. L. Dorset, G. J. Kennedy, Micropor. Mesopor. Mater. 2011, 142 , 168-177.

[34] J. Shin, S. B. Hong, Micropor. Mesopor. Mater. 2009, 124, 227-231.

[35] R. M. Barrer, Hydrothermal chemistry of zeolites, Academic Press, New York, 1982.

[36] W. J. Roth in Molecular Sieves: from Basic Research to Industrial Applications, Vol. 158A (Eds: J. Čejka, N. Žilková, P. Nachtigall), Stud. Surf. Sci. Catal., Elsevier, New York, 2005, pp. 19-26.

[37] M. Kubů, S. I. Zones, J. Čejka, Top. Catal. 2010, 53, 1330-1339.

[38] Y. J. He, G. S. Nivarthy, F. Eder, K. Seshan, J. A. Lercher, Micropor. Mesopor. Mater. 1998, 25, 207-224.

[39] A. S. Fung, S. L. Lawton and W. J. Roth, U.S. Patent 5,362,697, 1994.

[40] P. Chlubná, W. J. Roth, A. Zukal, M. Kubů, J. Pavlatová, Catal. Today 2012, $179,35-42$.

[41] B. Xiao, P. J. Bryne, P. S. Wheatley, D. S. Wragg, X. B. Zhao, A. J. Fletcher, M. Thomas, L. Peters, J. S. O. Evans, J. E. Warren, W. Z. Zhou, R. E. Morris, Nature Chem. 2009, 1, 289-294.

[42] J. F. Geng, W. Z. Zhou, P. Skelton, W. B. Yue, I. A. Kinloch, A. H. Windle, B. F. G. Johnson, J. Am. Chem. Soc. 2008, 130, 2527-2534.

[43] H. F. Greer, W. Zhou, Crystallogr. Rev. 2011, 17, 163-185.

[44] B. C. Lippens, J. H. de Boer, J. Catal. 1965, 4, 319-323.

[45] L. G. Joyner, E. P. Barrett, P. P. Halenda, J. Am. Chem. Soc. 1951, 73, 373-380.

[46] K. S. W. Sing, D. H. Everett, F. A. W. Haul, L. Mouscou, R. A. Pierotti, J. Rouquerol, T. Siemieniewska, Pure Appl. Chem. 1985, 57, 603-619. 
[47] A. Corma, U. Diaz, V. Fornes, J. M. Guil, J. Martinez Triguero, E. J. Creyghton, J. Catal. 2000, 191, 218-224.

[48] B. Gil, B. Marszałek, A. Micek-Ilnicka, Z. Olejniczak, Top. Catal. 2010, 53, 1340-1348.

[49] J. Datka, B. Gil, J. Fraissard, P. Massiani, P. Batamack, Pol. J. Chem. 1999, 73, $1535-1548$.

[50] B. Gil, S.I. Zones, S-J. Hwang, M. Bejblová, J. Čejka, J. Phys. Chem. C 2008 112, 2997-3007.

[51] H. Knözinger in Handbook of Heterogeneous Catalysis (Eds: G. Ertl, H. Knözinger, F. Schüth, J. Weitkamp), WILEY-VCH, Weinheim, 2008, pp. 1135 1163 .
[52] S. Goergen, E. Fayad, S. Laforge, P. Magnoux, L. Rouleau, J. I. Patarin, J. Porous Mat. 2011, 18, 639-650.

[53] A. Corma, M. J. Diaz-Cabanas, U.S. Patent App. 20080027247 A1, 2008

[54] L. M. Rohde, G. J. Lewis, M. A. Miller, J. G. Moscoso, J. L. Gisselquist, R. L. Patton, S. T. Wilson, D. Y. Jan, U.S. Patent 6,756,030, 2004.

Received: ((will be filled in by the editorial staff))

Revised: ((will be filled in by the editorial staff))

Published online: ((will be filled in by the editorial staff)) 
Entry for the Table of Contents (Please choose one layout only)

\section{Layout 1:}

New Family of Two-dimensional

Zeolites Prepared from the

Intermediate Layered Precursor

IPC-3P Obtained during the

Synthesis of TUN Zeolite

M. Kubi̊, W. J. Roth, H. F. Greer,

W. Zhou, R. E. Morris, J. Přech, J.

$\check{C}$ ejka*............ Page - Page

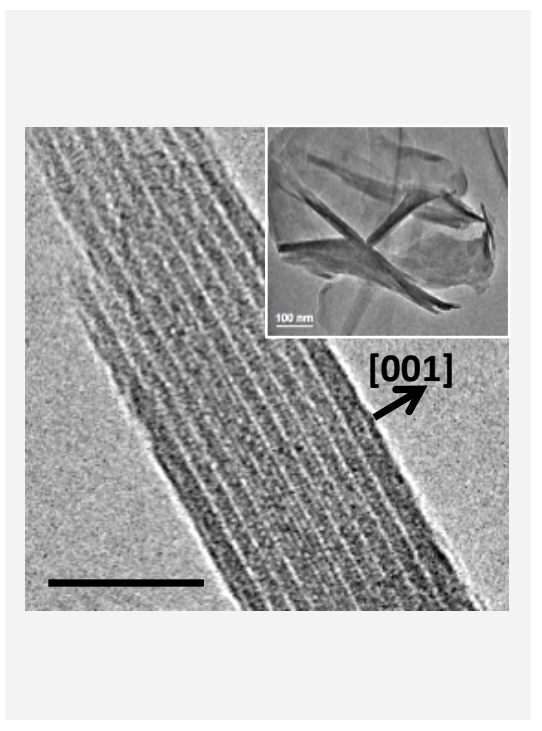

The crystallisation of zeolite TNU-9 (TUN) occurs via an intermediate layered precursor IPC-3P. The precursor is similar in nature to the precursors found for other zeolites, such as MWW, but but differs significantly in the ordering of the layers relative to each other. X-ray diffraction, electron microscopy and other techniques reveal the structure of the intermediate.

\section{Layout 2:}

\section{Catch Phrase}

Author(s), Corresponding

Author(s)* Page - Page

\section{Title Text}

((The TOC Graphic should not exceed the size of this area))

Text for Table of Contents, max. 450 characters.
Text for Table of Contents, continued. 